\title{
Risk Assessment in the Constructions Sector of EU Countries: Application of a Methodological Framework using Quantitative Techniques and Occupational Accidents' Data throughout the period 1996-2011
}

\author{
P. K. Marhavilas* and P. T. Vrountas \\ Department of Engineering Project Management (MSc), Hellenic Open University, Greece
}

Received 19 June 2017; Accepted 20 January 2018

\begin{abstract}
The subject of this work is the risk assessment, concentrating on the constructions' workplaces of EU countries. Two significant methodologies (adapted from the scientific litterature), as well as a combined elaboration (joint analysis) of their results, are used for this purpose. The first one, is the Proportional Risk Assessment Technique (PRAT) (see [1], [2], [3] ) and the second one, is the analysis of Time Series Processes (TSP) (see [4], [5] ), concerning occupational accidents. In particular, real data of occupational accidents in Greece, Cyprus, France, Germany and Spain, are analyzed (PRATTSP joint analysis). These data have been collected from different official State sources or databases, throughout various time intervals, namely: (i) for Greece by "SEPE" (Labor Inspectorate, Ministry of Employment) regarding the years 2001-2011 (ii) for Cyprus by the "Department of Labor Inspection of Cyprus" (DLIC) concerning the years 2003-2011 and (iii) for the countries Greece, France, Germany and Spain from the "Eurostat" database covering the period 19962007. The relevant results, show that the estimated value for the magnitude of risk (R) in the worksites of the constructions sector (Constructions and Public Works) is, in some cases, greater than 200, that proves, according to the scientific litterature, the necessity of taking measures no later than one year, in order to downgrade the direct risk of arising fatal accidents.
\end{abstract}

Keywords: risk assessment, occupational accidents construction worksite, technical work, quantitative technique, time series, statistical analysis

\section{Introduction}

The working environment in the field of engineering and in the constructions sector, is characterized by a dynamic feature including both the discovery of new manufacturing methods and the modernization of production technology, which however poses dangers to the health and safety of workers. Despite the development and implementation of a strict legislative framework, the risk to workers' health and safety, does not cease to exist and is even intensified in periods of intense economic activity and growth. In particular, technical projects in the constructions sector, due to their complexity and the unskilled personnel they use, have the specificity that their activities have a high degree of uncertainty and a variety of Undesired sources of risk. In other words, the technical works in the constructions sector, present in terms of occupational hazards, the highest risk. This deduction, is defined by two basic parameters: the number of accidents (especially the fatalities) recorded each year in the constructions sector, and on the other side, the workers' occupational diseases which are not direct in nature and are usually delayed in their appearance. Furthermore, it is necessary the understanding of (i) the risks of accidents and diseases in a construction site, (ii) their causes and (iii) the severity of their consequences they cause. This can be succeed by the development of control

*E-mail address: marhavil@ee.duth.gr

ISSN: 1791-2377 С 2018. Eastern Macedonia and Thrace Institute of Technology. All rights reserved. doi:10.25103/iestr.111.08 mechanisms in order to reduce the likelihood.

Taking into account the scientific literature, risk is defined, according to Woodruff, as "the chance that someone/something, which is valuated, will be adversely affected by the hazard" [6]. Moreover, it is recommended that a hazard is any potential source or any unsafe condition of one (or more) Undesired event (events) with potential for harm or for damage [7]. Furthermore, risk analysis is a vital tool for the safety policy of any organization, while risk estimation is a critical part of the whole practice of hazards evaluation in the workplaces, and particularly in the constructions sector, where the work-conditions are unsteady. Risk can be quantified and considered as an magnitude that can be expressed by a mathematical equation, in association with the usage of accidents data [5].

The aim of this paper is to assess the occupational risk in the workplaces in the constructions sector (constructions and public technical works) in various EU Countries, like Greece, Cyprus, France, Germany and Spain. It is worth noting, that a variety of techniques, methodologies and tools (which have been recorded in the international scientific bibliography), have been developed towards this direction. Risk assessment methods are divided into two major categories, depending on their approach. The first category includes methods that use the deterministic approach ([3], [5]). This category includes qualitative, semi-quantitative, quantitative and hybrid techniques. The second one, incorporates methods which use a probabilistic/stochastic approach, including the subclasses of the (i) classic 
statistical approach and (ii) accident prediction modeling ([8], [3]).

In particular, two important methods in risk analysis and assessment are used in this paper, which enable us to provide a satisfactory analysis of the available statistical data. The first one, is the Proportional Risk Assessment Technique (PRAT) (see [1], [2], [3]) and the second one, is the analysis of Time Series Processes (TSP), concerning occupational accidents (see [4], [5]). In addition, a combined analysis of these techniques is attempted, in order to extract useful findings, that will improve safety levels at construction sites.

More specifically, real data of occupational accidents in Greece, Cyprus, France, Germany and Spain, are analyzed. These data have been collected from different official State sources or databases, throughout various time intervals, namely: (i) for Greece by SEPE (Labor Inspectorate, Ministry of Employment) regarding the years 2001-2011 (ii) for Cyprus by the Department of Labor Inspection of Cyprus (DLIC) concerning the years 2003-2011 and (iii) for the countries Greece, France, Germany and Spain from the Eurostat database covering the period 1996-2007.

\section{Methodology}

\subsection{Proportional Risk Assessment Technique (PRAT)}

The Proportional Risk Assessment Technique (PRAT) (see [1], [2], [3], [5]) is a quantitative method, and is used for the assessment of operational risks. It applies a mathematical relation to calculate the "quantity" of risk (i.e. quantified risk evaluation). More specifically, this technique can be applied by the following equation:

$$
\mathrm{R}=\mathrm{P} \times \mathrm{F} \times \mathrm{S}
$$

where:

R: the corresponding Risk score

P: the Probability Factor (i.e. the occurrence likelihood/probability of the undesired/unwanted event)

S: the Severity of Harm/Damage Factor (i.e. the potential consequences of an accident/incident/undesired event)

F: the Exposure Factor (i.e. the occurrence frequency of the hazardous-events or the duration of the activity from which the unwanted event may result)

Consequently, risk is calculated by considering the potential consequences of an accident, the probability factor and the exposure factor. Unsafe situations are estimated (i) by means of exposure (which assesses the occurrence frequency of the hazard-event during a productive process) or (ii) by quantitative calculation of potentially hazardous circumstances to which employees are exposed (see [9], [10], [11], [5] and references therein).

The above concepts are made operational, thus the relation (1) becomes a practical numerical method for making a quantitative risk classification. It combines the factor of exposure with the factor of likelihood in order to unveil the frequency. Moreover, risk classification is significant as a tool to prioritize identified risks for further treatment (pre-event tool). The fundamental questions are the following: "how often could the unwanted event occur, in order to trigger the sequence from hazard towards consequences?" and "what/how large could these consequences be?" Risk classification is also an essential tool (post-event tool) for the accident/incident (or unwanted event) investigation ( $h t t p: / / w w w . t o p v e s . n l / r i s k$-managementresources.html).

The equation (1) creates a consistent system for safety management to set priorities for attention to harmful situations. The validity of these priorities/decisions is evidently a function of the power of the estimates of the factors $\mathrm{P}, \mathrm{S}$ and $\mathrm{F}$. These estimates, seemingly simple, require the collection of information, the visit of the worksites and the discussion with the employees about their activities [7]. The participation of the personnel is thus vital, because it knows exactly how the work is actually performed.

For risk calculations, numerical values are estimated for each factor of relation \#1, with the result the total risk score is computed by the product of the three separate factors. According to Kinney and Wiruth [9], the numerical values (although arbitrarily chosen) are self-consistent and together they provide a realistic but relative outcome for the whole risk. The occurrence likelihood of a hazardous/harmful event is related to the arithmetic probability which actually occur.

Nevertheless, due to practical purposes, probability is given by alternative terms of prospects. Likelihoods, which may be encountered in operable safety situations, range from the completely unexpected/unanticipated event (but remotely possible) up to an event, that could be expected at some future time. An example of an unanticipated event is the failure of a proof-tested container of compressed gases. For mathematical purposes the likelihood/probability factor for such an event is arbitrarily take the value of one (" 1 "). On the other side, an example of a hazardous/harmful event, which could be expected at a future moment, is combustible material catching on fire in a drying oven, mainly if this has happened in the recent past. The likelihood/probability factor for such an event is taken the value of ten "10"). These two probabilities provide reference points on a scale of likelihoods for ordinary hazardous/harmful events. Furthermore, situations between these two reference probabilities acquire intermediate values. For example, a "Frequent" type event takes a likelihood value equal to eight (“8”) [see Table 1].

As far as the exposure factor is concerned, the greater the exposure to a source of a danger, the greater is the risk value. In order to establish a suitable scale for this factor, the value of one is assigned to the situation of a rare exposure, for example in the fact that an undesired event appears every five years (see Table 3). Thus, the value of ten is assigned for continuous exposure. For intermediate values, interpolation is applied by using these two reference points, with the result the value of three is given in the situation of a monthly exposure. Besides, the application of extrapolation is necessary for situations of a very extraordinary exposure, and without a doubt the value of zero would be given for conditions of no exposure at all.

To continue, the severity of harm/damage factor, describing the hurt from a harmful event, can range from minor harm (no one human injury) that is hardly noticeable up to the disastrous (fatal or lethal accident) [see Table 2].

Taking into account Tables 1, 2, 3 we assign values in each factor of equation (1), in the scale of " $1-10$ ", so that the magnitude of risk (R) can be expressed in the range of "1- 
1000". We note that Tables 1, 23 were produced by using the thesis of Marhavilas [5].

In particular, Table 1 depicts the gradation of the Likelihood/Probability Factor $(\mathrm{P})$ in association with the hazard/danger sources. Table 2 illustrates the gradation of the hazard source severity S (Severity of Harm Factor), while Table 3 reflects the gradation of the exposure factor (F). Concerning the gradation of $\mathrm{P}$, the value of 1 corresponds to likelihood/probability of $10 \%, \mathrm{P}=2$ to likelihood of $20 \%, \mathrm{P}=3$ to likelihood of $30 \%$, etc. We emphasize the possible existence of intermediate values, e.g. value $\mathrm{P}=3.2$, corresponds to probability of $32 \%$.

Moreover, by using Table 4 we can associate the gradation of risk outcome (R) with the urgency level of essential actions.

To construct Table 4, we assign values to $\mathrm{P}$ and $\mathrm{S}$ so that the $\mathrm{F}$ (frequency or exposure factor) could determine the urgency level of the necessary actions. Therefore, we act as follows:

- To take into account the worst case, we assign the maximum value of ten ("10") in the Probability Factor (P) and Severity of Harm Factor (S) respectively.

- We divide the range of $F$ into such partitions as making the sets of: $\mathrm{F} 1=[1,2], \mathrm{F} 2=[2,3], \mathrm{F} 3=[3,5]$, $\mathrm{F} 4=[5,7], \mathrm{F} 5=[7,10]$ (Table 3$)$

- By using the relation $\mathrm{R}=\operatorname{PxSxF}_{\mathrm{i}}(\mathrm{i}=1,2,3,4,5)$, we create for $R$ the following sets: $R_{1}=[100,200]$, $\mathrm{R}_{2}=[200,300], \quad \mathrm{R}_{3}=[300,500], \quad \mathrm{R}_{4}=[500,700]$, $\mathrm{R}_{5}=[700,1000]$

- Consequently, the urgency level of the compulsory actions could be determined by the features of the lower limit of the previous referred sets. For example, the set $R_{2}=[200,300]$ has a lower limit of $\mathrm{R}=200$, i.e. $\mathrm{F}=2(\mathrm{P}=10$ and $\mathrm{S}=10)$, that means the urgency level of required actions must be 1 year, in order to be eliminated the damage that occurs every 1 year (as the exposure factor is $\mathrm{F}=2$ ).

We note that the concept of probability is very significant in safety science and also for risk. In addition, there is considerable discussion within the scientific community about the meaning and explanation of probabilities. Two severe issues are present: the issue of the so-called objectivist probabilities (or frequentists) and that of the so-called subjectivist probabilities. According to the previous perspective, probabilities mean the limiting relative fraction of specified occurrences. A frequentist probability of an event $\mathrm{A}$ is defined as the relative fraction of times the event A occurs [if the situation considered were repeated (hypothetically) an infinite number of times]. A "frequentist probability" is thus a model concept, founded on the law of large numbers saying that frequencies $\mathrm{n}_{\mathrm{A}} / \mathrm{n}$ converge to a limit under certain conditions. An alternative approach is to simply assume the existence of the probability, and then apply the law of large numbers to assign the limiting frequentist interpretation (see [12], [13], [14]).

Although most random phenomena do not have equally likely results, it could be helpful to define a sample-space in such a way that the results are at least approximately equally possible, since this condition significantly simplifies the calculation of likelihoods for events within the sample- space. If each individual result occurs with the same probability, then the likelihood of any event equals:

$$
\begin{aligned}
& \mathrm{P}(\text { event })=[\text { number of outcomes in event }] / \\
& \text { [number of outcomes in sample-space }]
\end{aligned}
$$

For instance, in the case of tossing a single six-sided die, the characteristic sample-space is \{ $1 "$, " 2 ", " 3 ", “4", " 5 ", "6" $\}$, in which the result of interest is the number of pips facing up, and the probability of the event "the result is 4 ", is $P(" 4 ")=1 / 6$.

Taking into account the previous paragraph, and the fact, that the likelihood of occurrence of a hazardous/harmful event is related to the mathematical probability that it might actually occur, we approach, for practical purposes, the probability of occurrence of the unwanted event, with the relative fraction of specified accidents. In particular, the accidents represent the consequences of the sources of the hazardous/undesired events, the sample-space is depicted by the elements of the accidents set, and thus the likelihood of occurrence of an undesired event, i.e. the relative frequency-interpreted probability is:

\section{$\mathrm{P}($ undesired event $)=$ \\ (number of resulted accidents in this event) / \\ (number of resulted accidents in sample-space)}

The statistical data of SEPE (throuhout the years 20012011), the DLIC (years 2003-2011) and Eurostat (years 1996-2007), concerning the accidents number at work, which caused and recorded on the constructions sites, were analyzed and elaborated in order to assess the risk by using the relationship (1).

In particular, the probability factor (or index) $\mathrm{P}$ is calculated for each cause of an accident, by using quantitative data of accidents and the above relation (3) as follows:

\section{$\mathrm{P}=$ Number of Accidents per Category / \\ Total Number of Accidents}

The severity score $\mathrm{S}$ is assessed empirically by the safety officer, taking into account the worst case and using the gradation scale of Table 2 .

The Frequency Index (or Exposure Factor) F illustrates the amount of accidents during a specific time interval. Thus, in order to compute the accidents frequency (f), we use data for time interval of 1 year (that includes 48 working weeks with 5 working days, each week) in the equation:

$$
\mathrm{f}(\text { Event frequency })=\frac{\text { Number of Accidents per Category }}{48 \times 5}
$$

The index/factor $\mathrm{F}$ follows from the mapping of the output of equation (5) based on the grading scale of Table 3. It is noted that the intermediate values have been obtained by linear interpolation.

\subsection{Time Series Processes Analysis (TSP) - The PRAT- TSP Combined Analysis}

Figure 1 illustrates the flowchart of the proposed methodological framework, which combines a deterministic 
risk assessment technique, the "PRAT" one, with a stochastic technique, i.e. the analysis of Time Series Processes (TSP) of occupational accidents' data [15].

Table 1. Gradation of Probability-Factor $(\mathrm{P})$ as far as the undesired event (or source of danger) is concerned

\begin{tabular}{cl}
\hline Probability Factor [P] & \multicolumn{1}{|c}{ Description of Undesired Event } \\
\hline 10 & "Unavoidable" \\
9 & "Almost assured" \\
8 & "Frequent" \\
7 & "Probable" \\
6 & "Probability slightly greater than \\
$50 \% "$ \\
5 & "Probability 50\%" \\
4 & "Probability slightly less than \\
& $50 \% "$ \\
3 & "Almost improbable (or Remote)" \\
2 & "Improbable" \\
1 & "Impossible" \\
\hline
\end{tabular}

Table 2. Gradation of the Severity of Harm/Damage Factor (S) as far as the undesired event (or source of danger) is concerned

\begin{tabular}{c|l}
$\begin{array}{c}\text { Severity of } \\
\text { Harm/Damage } \\
\text { Factor (S) }\end{array}$ & \multicolumn{1}{c}{ Description of Undesired Event } \\
\hline 10 & "Death" \\
9 & "Permanently total-inefficiency" \\
8 & $\begin{array}{l}\text { "Permanently serious-inefficiency" } \\
\text { "Permanently slight-inefficiency" } \\
\text { "Absence from the work (for more than } 3 \\
\text { weeks) and return with health-problems" } \\
\text { "Absence from the work (for more than } 3 \\
\text { weeks) and return after full recovery" } \\
\text { "Absence from the work (for more than } 3 \\
\text { days and less than 3 weeks), and return after } \\
\text { full recovery" } \\
\text { "Absence from the work (for less than } 3 \\
\text { days) and return after full recovery" } \\
\text { "Slight injuring without absence from the } \\
\text { work, and with full recovery" } \\
\text { "No one human injury" }\end{array}$ \\
\hline
\end{tabular}

Table 3. Gradation of the Frequency Factor (or the Exposure Factor) (F) as far as the undesired event (or source of danger) is concerned

\begin{tabular}{c|l}
$\begin{array}{c}\text { Frequency (or } \\
\text { Exposure) } \\
\text { Factor (F) }\end{array}$ & \multicolumn{1}{|c}{ Description of Undesired Event } \\
\hline 10 & $\begin{array}{l}\text { "Permanent presence of damage" } \\
\text { "Presence of damage/harm every } 30 \\
\text { sec" } \\
\text { "Presence of damage/harm every 1 } \\
\text { min" } \\
\text { "Presence of damage/harm every 30 } \\
\text { min" } \\
\text { "Presence of damage/harm every 1 hr" } \\
\text { "Presence of damage/harm every } 8 \\
\text { hr(or 1 working shift)" } \\
\text { "Presence of damage/harm every 1 } \\
\text { week" } \\
\text { "Presence of damage/harm every 1 } \\
\text { month" } \\
\text { "Presence of damage/harm every 1 } \\
\text { year" } \\
\text { "Presence of damage/harm every } 5 \\
\text { years" }\end{array}$ \\
\hline
\end{tabular}

Table 4. Gradation of the Risk score (R) as far as the urgency level of essential actions is concerned

\begin{tabular}{|c|c|}
\hline $\begin{array}{c}\text { Risk } \\
\text { Value/Score } \\
\text { (R) } \\
\end{array}$ & Urgency level of essential actions \\
\hline $700-1000$ & "Immediate action" \\
\hline $500-700$ & "Required Action earlier than one day" \\
\hline $300-500$ & "Required Action earlier than one month" \\
\hline $200-300$ & "Required Action earlier than one year" \\
\hline$<\mathbf{2 0 0}$ & $\begin{array}{l}\text { "Immediate action is not necessary but it is } \\
\text { required the event surveillance" }\end{array}$ \\
\hline $100-200$ & - Long-term action \\
\hline$<100$ & $\begin{array}{l}\text { - Required action is not necessary, but it is } \\
\text { required the event's surveillance }\end{array}$ \\
\hline
\end{tabular}

The "TSP" technique belongs to the stochastic approaches, and more specifically in the category of accident prediction models, and uses actual accident data to predict future outcomes [4]. The main tools used in the time series analysis are: the graph analysis, the $\mu$-average analysis, the current-average analysis, the trend analysis, the periodicities-analysis, etc.

According to PRAT-TSP methodological framework of Figure 1, real accidents' data, recorded from the constructions' sector workplaces, constitute the input data, both to PRAT technique, and also to TSP analysis. In addition, the output data from the PRAT module, constitute the input data to TSP analysis. Eventually, the results derived from the calculation of risk (by PRAT), and the outcome results from TSP tools, are further jointly analyzed, in order to extract useful conclusions for the safety level of the constructions sector workplaces.

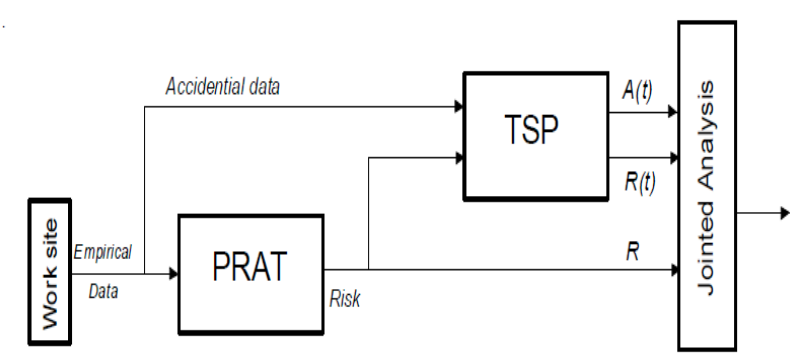

Fig. 1. The flowchart of a proposed methodological framework, based on combination of risk analysis and techniques and [Marhavilas and Koulouriotis 2012]

\section{Selected Data and Results}

In Table 5, which shows for the Greek constructions sector (based on the SEPE statistical database), the results of the PRAT application during the year 2006, we observe that the accident with cause "Slipping, falls, missteps" has the highest risk value of $\mathrm{R}=210.29$. Consequently, according to Table 4, it is necessary to take measures within one year. On the other side, the danger (or risk) source of "Overflow, overturn, leakage, flow, exhaust, emission" presents the lowest risk of 4.81 , and the rest ones presents risk score lower than 100 . So, it is not necessary to take immediate actions, but to monitor the Undesired events as they present $\mathrm{R}<100$. 
Table 5. Statistical accidents data for Greek constructions sector, taking into account the database of SEPE (Hellenic Ministry of Employment) for the year 2006 (columns A and B), evaluation of index S (column D), and computation of indices $\mathrm{P}, \mathrm{F}$ (columns $\mathrm{C}$ and $\mathrm{E}$ ) and risk score of $\mathrm{R}$ (column F)

\begin{tabular}{l|c|c|c|c|c}
\hline \multicolumn{1}{c|}{$(\mathbf{A})$} & $\mathbf{( B )}$ & $\mathbf{( C )}$ & $\mathbf{( D )}$ & $\mathbf{( E )}$ & $\mathbf{( F )}$ \\
\hline $\begin{array}{c}\text { Description of } \\
\text { Undesired Event }\end{array}$ & $\begin{array}{c}\text { Accident } \\
\text { Number }\end{array}$ & $\mathbf{P}$ & $\mathbf{S}$ & $\mathbf{F}$ & $\mathbf{R}$ \\
\hline $\begin{array}{l}\text { Electrical problems, } \\
\text { explosion, fire }\end{array}$ & 35 & 0.439 & 10 & 3.638 & 15.97 \\
$\begin{array}{l}\text { Slipping, falls, } \\
\text { missteps }\end{array}$ & 367 & 4.604 & 9 & 5.075 & 210.29 \\
$\begin{array}{l}\text { Fracture, crack, } \\
\text { disruption, downfall, } \\
\text { collapse of material } \\
\text { factor }\end{array}$ & 142 & 1.781 & 10 & 4.489 & 79.95 \\
$\begin{array}{l}\text { Overflow, overturn, } \\
\text { leakage, } \\
\text { evaporation, } \\
\text { emission }\end{array}$ & 14 & 0.175 & 9 & 3.055 & 4.81 \\
$\begin{array}{l}\text { Movement with } \\
\text { physical tension }\end{array}$ & 17 & 0.213 & 8 & 3.138 & 5.35 \\
$\begin{array}{l}\text { Loss of control of } \\
\text { the machine, } \\
\text { transportation, hand } \\
\text { tool, object } \\
\begin{array}{l}\text { Other Causes } \\
\text { Total }\end{array}\end{array}$ & 128 & 1.606 & 10 & 4.416 & 70.92 \\
\hline
\end{tabular}

Table 6 dipicts for the Greek constructions' sector and specifically for the danger source "Electrical problems, explosion, fire" the time series of accidents $\mathrm{A}(\mathrm{t})$ adapted from the SEPE database, throughout the period 2001-2011, and also the calculated risk values of $\mathrm{R}(\mathrm{t})$, followed by the corresponding graphs (Figure 2 and 3 ).

In the graph of Figure 2 where it is depicted the accident time series $\mathrm{A}(\mathrm{t})$ concerning the danger source "Electrical problems, explosion, fire", a downward trend (according to the straight line of the mean value) is noticeable with strong fluctuations. This graph also reveals a discernible periodicity pattern, with maximum approximately every six years (e.g. a period of $6 \mathrm{yrs}$ ). At the same time, the running (or moving) average shows a stability from 2003 to 2007, and from 2007 onwards it continues to decline. Furthermore, the graph of Figure 3, which refers to the time series of the risk score $\mathrm{R}(\mathrm{t})$ for "Electric problems, explosion, fire", shows a downward trend with strong fluctuations. We also observe a periodicity pattern with maximum every $4-5$ years.

Continuing, the drawing of Figure 4 illustrates for the Cypriots constructions (covering the years 2001-2011) the time series of the risk score $\mathrm{R}(\mathrm{t})$ for "Loss of control of the machine, means of transport, hand tool, object", and shows an upward trend with strong fluctuations, and also a periodicity pattern with maximum every $\sim 2$ years (the primary data adapted from the DLIC database, Cyprus).

The curves in Figure 5, compares the time series of the risk score $\mathrm{R}(\mathrm{t})$ for "Loss of control of the machine, means of transport, hand tool, object", between Greece and Cyprus and show strong fluctuations, and also a periodicity pattern with maximum every $\sim 2$ years (the primary data adapted from the SEPE/Creece and DLIC/Cyprus database).

Finally, the graphs of Figure 6, illustrate the time series of the total accidents number $\mathrm{A}(\mathrm{t})$ [column (a)] and the calculated risk scores $\mathrm{R}(\mathrm{t})$ [column $(\mathrm{b})$ ], concerning all danger sources in Constructions Sector workplaces, in
France (violet line), Germany (black line), Greece (blue line), and Spain (red line), throughout the period 1996-2007. A downward trend is noticeable in the time series of $\mathrm{A}(\mathrm{t})$ and $\mathrm{R}(\mathrm{t})$ for all countries after the year 1999 (the primary data adapted from the Eurostat database).

Table 6. Time series of accidents $A(t)$ and risk $R(t)$ concerning the danger source (or Undesired event) "Electrical problems, explosion, fire" adapted from the SEPE database, throughout the period 2001-2011

\begin{tabular}{c|c|c}
\hline TIME $\mathbf{t}$ & $\mathbf{A}(\mathbf{t})$ & $\mathbf{R ( t )}$ \\
\hline 2001 & 41 & 16,99 \\
2002 & 37 & 12,89 \\
2003 & 29 & 9,32 \\
2004 & 23 & 8,20 \\
2005 & 33 & 17,31 \\
2006 & 35 & 15,97 \\
2007 & 37 & 16,48 \\
2008 & 27 & 10,56 \\
2009 & 10 & 5,58 \\
2010 & 10 & 13,26 \\
2011 & 3 & 3,71 \\
\hline
\end{tabular}

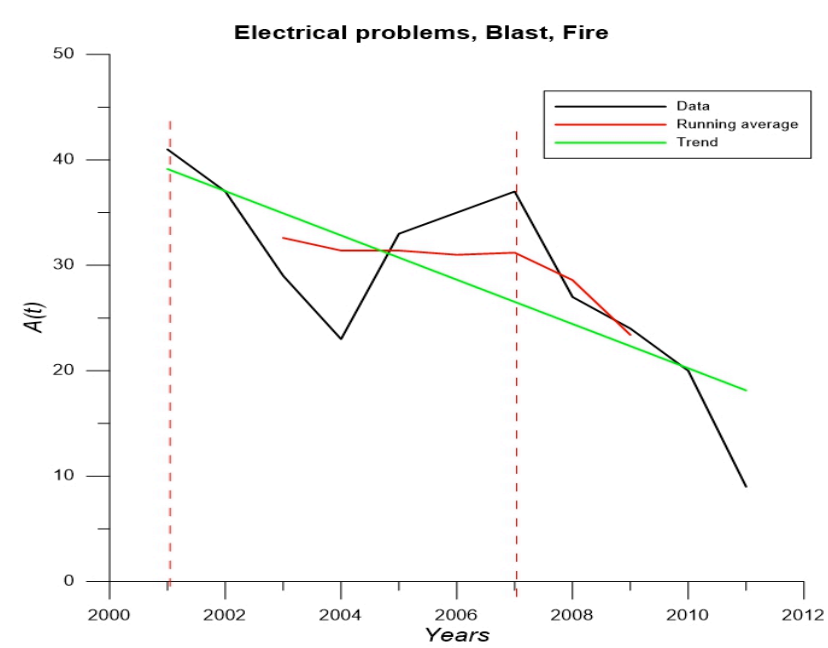

Fig. 2. This graph depicts the accident time series $\mathrm{A}(\mathrm{t})$ concerning the danger source "Electrical problems, explosion, fire". A downward trend is noticeable with strong fluctuations, and also a discernible periodicity pattern, with maximum every (i.e. a period of) $\sim 6$ years (the primary data adapted from the SEPE database, Greece)

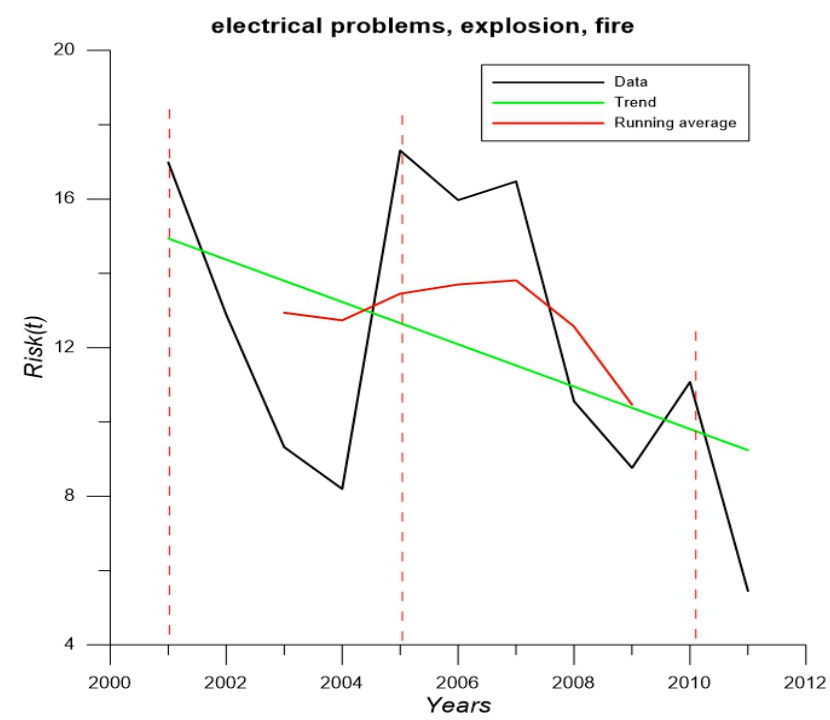

Fig. 3. This graph refers to the time series of the risk score $R(t)$ for "Electric problems, explosion, fire", and shows a downward trend with 
strong fluctuations, and also a periodicity pattern with maximum every 4-5 years (the primary data adapted from the SEPE database, Creece)

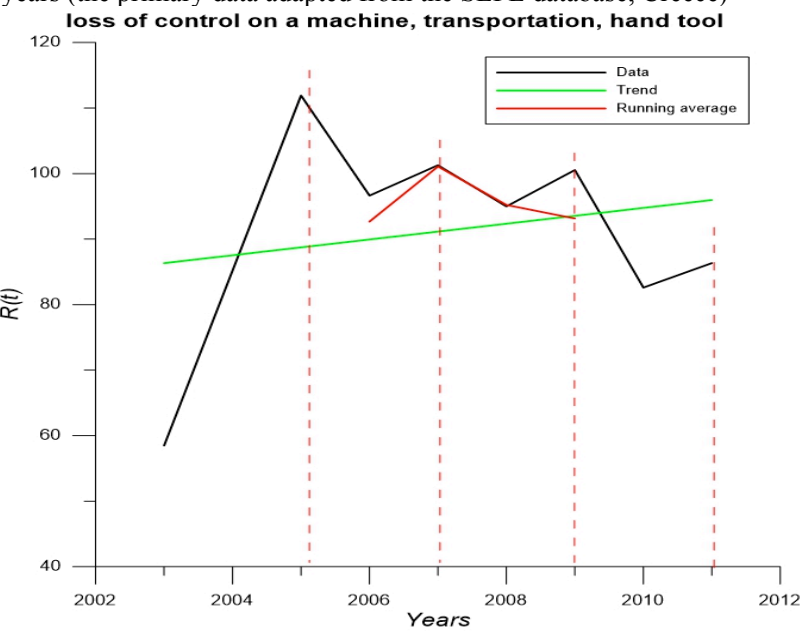

Fig. 4. This graph refers to the time series of the risk score $R(t)$ for "Loss of control of the machine, means of transport, hand tool, object", and shows an upward trend with strong fluctuations, and also a periodicity pattern with maximum every $\sim 2$ years (the primary data adapted from the DLIC database, Cyprus)

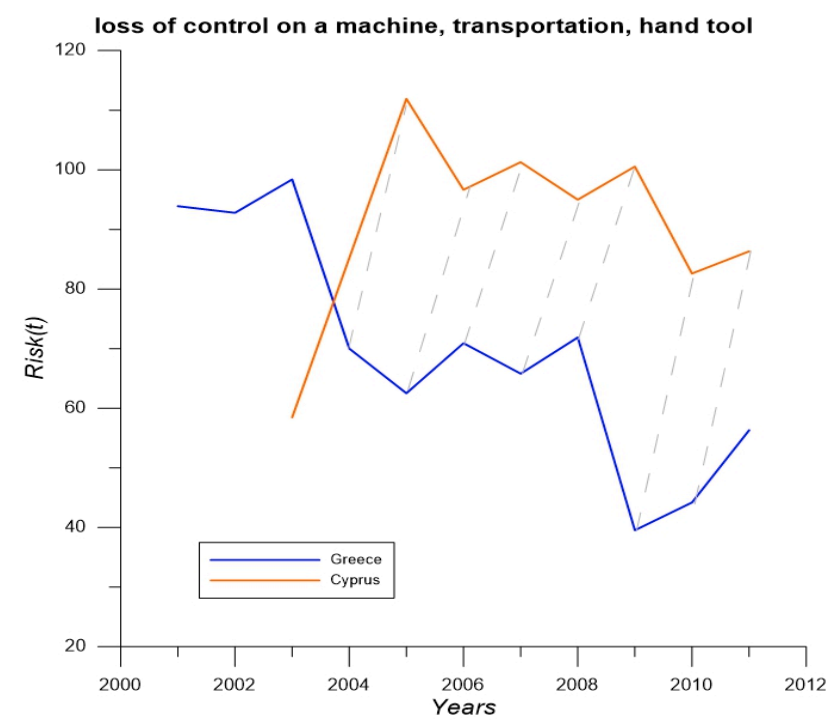

Fig. 5. This graph compares the time series of the risk score $R(t)$ for "Loss of control of the machine, means of transport, hand tool, object", between Greece and Cyprus and shows strong fluctuations, and also a periodicity pattern with maximum every $\sim 2$ years (the primary data adapted from the SEPE/Creece and DLIC/Cyprus database)

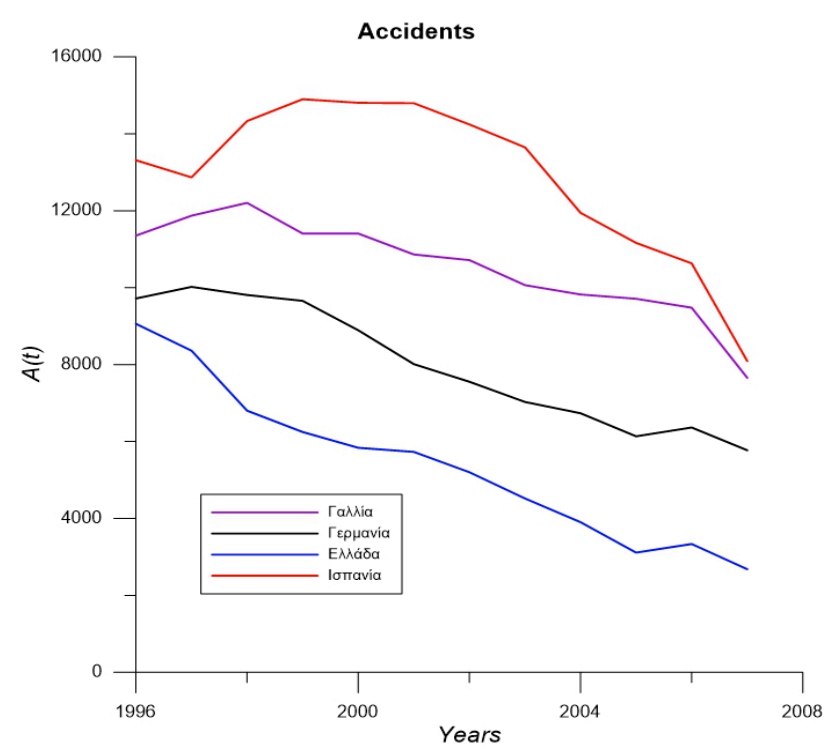

(a)

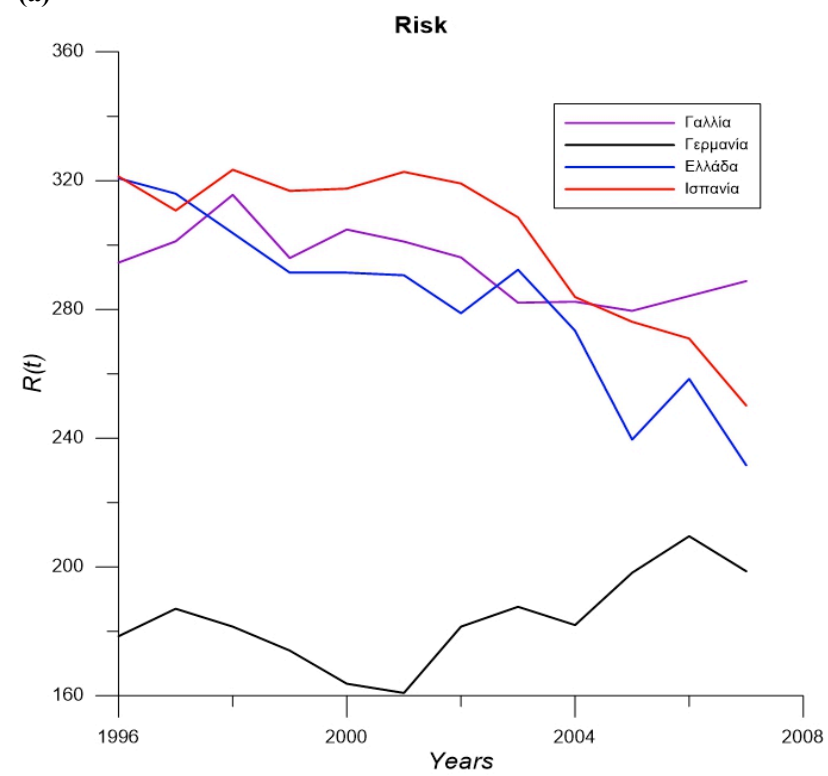

(b)

Fig. 6. The graphs illustrate the time series of (a) the total accidents number $\mathrm{A}(\mathrm{t})$ and (b) the calculated risk scores $\mathrm{R}(\mathrm{t})$, concerning all danger sources in Constructions Sector workplaces, in France (violet line), Germany (black line), Greece (blue line), and Spain (red line), throughout the period 1996-2007. A downward trend is noticeable in the time series of $\mathrm{A}(\mathrm{t})$ and $\mathrm{R}(\mathrm{t})$ for all countries after the year 1999 (the primary data adapted from the Eurostat database)

\section{Discussion-Conclusions}

The main aim of this work is the risk assessment, concentrating on the workplaces of the constructions sector of EU countries. Two significant methodologies (adapted from the scientific litterature), as well as a combined analysis (joint analysis) of their results, are used for this purpose (see the flowchart of Figure 1). The first one, is the Proportional Risk Assessment Technique (PRAT) (see [16], [1], [2], [3], [5]) and the second one, is the analysis of Time Series Processes (TSP), concerning occupational accidents (see [4], [5]).

In particular, real data of occupational accidents in Greece, Cyprus, France, Germany and Spain, have been elaborated (by PRAT-TSP joint analysis). These data have 
been collected from different official State sources or databases, throughout various time intervals, and specifically: (i) for Greece by "SEPE" (Labor Inspectorate, Ministry of Employment) regarding the years 2001-2011 (ii) for Cyprus by the "Department of Labor Inspection of Cyprus" (DLIC) concerning the years 2003-2011 and (iii) for the countries Greece, France, Germany and Spain by the "Eurostat" database covering the period 1996-2007. In this paper, we present as examples, selected data analysis and graphs (Figures 2, 3, 4, 5, 6, and Tables 5, 6).

In general, one of the most important findings for Greek constructions worksites, with regard to PRAT analysis, is the consistently high risk [with a per-year risk-score $\mathrm{R}(\mathrm{t})$, exceeding the limit of 200] the Undesired event (or danger source) "Slipping, falls, missteps" reveals during the period 2001-2011. According to this analysis, the curve of $R(t)$ presents a downward trend over time and unveils a periodicity pattern with a maximum every (i.e. a period of) $\sim 3$ years.

Another important (but serious for the Greek constructions sector) result is the particularly high risk-value $\mathrm{R}(\mathrm{t})$, the danger source "Other Causes" reveals throughout the period 2001-2011. The data analysis showed the appearance of risk values $\mathrm{R}(\mathrm{t})>150$, that means, long-term actions are necessary, and also the events' surveillance. Taking into account, that no discernible potential causes can be identified due to this danger source, which could create dangerous hazards, necessary attention should be given to this. Furthermore, as far as the other sources of risk (of Table 5) are concerned, the calculated risk values were below the limit of 100 , which means that there is a need to monitor the phenomena that cause the risk.

In addition, apart from Greece, we performed similar PRAT-TSP joint analysis on real data of occupational accidents in Cyprus (years 2001-2011) and France, Germany and Spain (years 1996-2007), with the result: the appearance of periodicity patterns, in almost all time-series, either in risk values $\mathrm{R}(\mathrm{t})$ or in accidents numbers $\mathrm{A}(\mathrm{t})$ profiles. The appearance and analysis of the rising periodicities can make an important contribution to accidents prevention. In particular, the existence of periodicities (or periodic factors) in the profile of accident time-series $A(t)$ and/or in the profile of risk-outcomes $\mathrm{R}(\mathrm{t})$, constitutes a considerable feature for the dynamic behavior of Constructions-Sector system, relatively to safety. Therefore, it could be taken into account by the Ministry of Health (and also by the Constructions-Companies risk-managers) in order to achieve efficient risk-management results. Moreover, urgent suppressive measures could be taken place to eliminate the danger source, that is originated from the periodic appearance of the most significant hazard/danger sources [4].

In the examined data for Cyprus, the danger source that consistently had the highest values during the years 20012011, was "breaking, splitting, slipping, falling material breakdown", while other danger sources which were less risky $(\mathrm{R}<150)$ were "Loss of control of the machine, means of transport, hand tool, object" (see Figure 4) and
"Overflow, overturn, leakage, evaporation, emission". The existence of strong fluctuations, with a periodicity pattern in the profiles of $\mathrm{R}(\mathrm{t})$ was obvious as well (e.g. Figure 4). The comparative analysis, between Greece and Cyprus, for "Loss of control of the machine, means of transport, hand tool, object" (see Figure 5) has the result, that the time series of the calculated risk score $\mathrm{R}(\mathrm{t})$ : (i) present similar (but with phase shifting) profiles, (ii) the $\mathrm{R}(\mathrm{t})$ curve for Greece is, in general, lower than the corresponding of Cyprus, (iii) unveil as main feature the existence of strong fluctuations, and (iv) reveal periodicity patterns with maximum every $\sim 2$ years.

Moreover, the comparative analysis of the total (i.e. nonnormalized) accidents number A(t) [in Figure 6.a] regarding France (with a population of 66.8 million people), Germany (with 81.4 million people), Greece (with 10.8 million people) and Spain (with 46.5 million people), throughout the period of 1996-2007, shows that Greece presents the lowest accidents number in Constructions Sector worksites, while Spain the highest ones. This finding is absolutely comprehensible, especially for Greece, which has the lowest population in comparison with the other three previous referred EU countries. On the other side, the curves of the calculated risk-scores $\mathrm{R}(\mathrm{t})$ [in Figure 6.b] afford a sufficient normalization for the comparative elaboration and analysis of the primary data, adapted from the Eurostat database. So, Germany presents the lowest risk-scores, during the period of 1996-2007, while Spain the highest ones, during the years 1997-2004, and France the highest ones, during the years 2005-2007. A declining trend is noticeable in the time series of $A(t)$ and $R(t)$ for all countries, since 1999.

The curves of Germany are impressive, as though it has the greatest population in EU Countries, presents, on the one hand, a low number of accidents (lower than France and Spain, and only greater than Greece), and on the other hand, the lowest risk-values compared with the other three previous referred EU countries.

This study expands the results of a previous one of Marhavilas and Vrountas [17]. In particular, the contribution of this study to the scientific field of occupational health and safety could be depicted by the following main points:

- Risk prediction and prevention: The combined application of two important techniques (included in the literature), as well as the combined elaboration and joint analysis of the accidents data, are used for this purpose. The presented new quantitative risk assessment technique could help safety managers to predict unsafe conditions and prevent fatal accidents.

- Application of this new technique in accidents data of the constructions sector of EU countries, in such a way that makes the new method a useful tool for the risk assessment.

This is an Open Access article distributed under the terms of the Creative Commons Attribution License

\section{References}

1. Marhavilas, P.K. Koulouriotis, D.E., "A risk estimation methodological framework using quantitative assessment techniques and real accidents' data: application in an aluminum extrusion industry". Journal of Loss Prevention in the Process Industries, 21, 6, 2008, p.p. 596-603. 
2. Marhavilas, P.K., "Risk Estimation in the Greek Constructions' Worksites by using a Quantitative Assessment Technique and Statistical Information of Occupational Accidents". Journal of Engineering Science and Technology Review, 2(1), 2009, pp. 5155.

3. Marhavilas, P.K., Koulouriotis, D.E., Gemeni, V., "Risk Analysis and Assessment Methodologies in the Work Sites: On a Review, Classification and Comparative Study of the Scientific Literature of the Period 2000-2009". Journal of Loss Prevention in the Process Industries, 24, 5, 2011, pp. 477-523.

4. Marhavilas, P.K., Koulouriotis, D.E., Spartalis, S.H., "Harmonic analysis of occupational-accident time-series as a part of the quantified risk evaluation in worksites: Application on electric power industry and construction sector". Reliability Engineering and System Safety, 112, 2013, pp. 8-25.

5. Marhavilas, P.K., "Risk Assessment Techniques in the Worksites of Occupational Health-Safety Systems with Emphasis on Industries and Constructions". PhD Dissertation, Democritus University of Thrace, Faculty of Engineering, Department of Production \& Management Engineering, 2015, pp. 1-320.

6. Woodruff, J. M., "Consequence and likelihood in risk estimation: A matter of balance in UK health and safety risk assessment practice". Safety Science, 43, 2005, pp. 345-353.

7. Reniers, G.L.L., Dullaert, W., Ale, B.J.M, Soudan, K., "Developing an external domino prevention framework: Hazwim". Journal of Loss Prevention in the Process Industries, 18, 2005, pp. 127-138.

8. Zheng, X., Liu, M., "An overview of accident forecasting methodologies". Journal of Loss Prevention in the Process Industries, 22, 2009, pp. 484-491.
9. Kinney, G.F. Wiruth, A.D., "Practical Risk Analysis for Safety Management". In: Naval Weapons Center, NTIS report number NWC-TP-5865, 1976, pp.70-85.

10. Van der Hoeven, E.T., Marking, C.E., "Creating a model for applying the EMC, LVD, and Machinery Directive”. MSc Thesis, University of Twente, School of Management and Governance, 2012.

11. Gangolells, M., Casals, M., Forcada, N., Roca, X., Fuertes, A., "Mitigating construction safety risks using prevention through design". Journal of Safety Research, 41(2), 2010), pp. 107-122.

12. Aven, T., "On how to define, understand and describe the risk". Reliability Engineering and System Safety, 95, 2010, pp. 623-631.

13. Aven, T., Reniers, G., "How to define and interpret a probability in a risk and safety setting”. Safety Science, 51, 2013, pp. 223-231.

14. Goerlandt, F., Montewka, J., "Maritime transportation risk analysis: Review and analysis in light of some foundational issues". Reliability Engineering and System Safety, 138, 2015, pp. 115134.

15. Marhavilas, P.K., Koulouriotis, D.E., "A combined usage of stochastic and quantitative risk assessment methods in the worksites: Application on an electric power provider". Reliability Engineering and System Safety, 97, 2012, pp. 36-46.

16. Fine, W.T., Kinney, W.D., "Mathematical evaluation for controlling hazards". Journal of Safety Research, 3(4), 1971, pp. 157-166.

17. Marhavilas, P.K., Vrountas, P., "Risk assessment in the Constructions Sector by using quantitative techniques and accidents data". Journal of Occupational Health and Safety, Hellenic Institute for Occupational Health and Safety, 70, 2017, pp. 16-33. 